\title{
The syllable as the proximate unit in Mandarin Chinese word production: An intrinsic or accidental property of the production system?
}

\author{
Train-Min Chen • Jenn-Yeu Chen
}

Published online: 12 October 2012

(C) Psychonomic Society, Inc. 2012

\begin{abstract}
Previous word production research employing the implicit-priming paradigm has shown that speakers can benefit from advance knowledge of the initial word form of the word to be produced. In Dutch and English, a single onset segment is sufficient to produce the benefit, but a complete syllable (without the tone) is required in Mandarin Chinese. These findings have been interpreted as suggesting language-dependent proximate units for word-form encoding, which are intrinsic to a language-specific system. Nonetheless, the absence of a segment effect in Mandarin Chinese might have to do with the orthographic characteristics of the prompts, which are syllable-based and could have motivated the production system to place more emphasis on the syllable than on the segment. Two experiments were conducted to test this hypothesis. In Experiment 1, we employed the implicitpriming paradigm with both spoken and written prompts, and in Experiment 2 we adopted a picture version of this paradigm. Spoken prompts are less likely to encourage an orthographically induced syllable bias, and picture naming involves no prompts, leaving no room for any syllable bias that prompts might induce. The results from both experiments showed syllable preparation effects but no segment preparation effects, regardless of whether prompts were written, spoken, or absent. These findings suggest that the syllable as the proximate unit in Mandarin Chinese word production is an intrinsic, and not an accidental or task-dependent, property of the production system.
\end{abstract}

T.-M. Chen

Department of Psychology, National Cheng Kung University,

Tainan, Taiwan

T.-M. Chen $(\bowtie) \cdot$ J.-Y. Chen

Department of Chinese as a Second Language,

National Taiwan Normal University,

162 Heping East Road, Sec. 1,

Taipei 106, Taiwan

e-mail: trainmin@gmail.com
Keywords Mandarin Chinese · Word production · Proximate unit $\cdot$ Implicit priming

Producing a word involves accessing its abstract phonological contents from the mental lexicon and assembling them into units of the proper size, so that these units can be mapped onto articulatory movements during speaking. This process is known as word-form encoding. According to the word production model proposed by Levelt, Roelofs, and Meyer (1999), the phonological contents selected at the beginning of word-form encoding are segments rather than syllables. The syllables are constructed online via a segment-to-frame association procedure. This proposal is consistent with the phonological characteristics of the languages that the model is built upon - that is, Dutch and English - in which resyllabification is often required in connected speech, such that the syllables of a word are best constructed online rather than stored and retrieved. The main evidence supporting the segment as the first unit selected for word-form encoding in Dutch and English has been obtained with the implicitpriming task. In this task, participants repeatedly name a set of words, which do or do not overlap in their initial segment (s). Consistent segment preparation effects (i.e., faster response times when there was overlapping than when there was not) have been observed, and these effects increased with the expansion of the overlap (Meyer, 1991).

The first unit selected for word-form encoding seems to be different in non-Indo-European languages. For example, in Japanese, the unit has been shown to be the mora (Kureta, Fushimi, \& Tatsumi, 2006; Verdonschot et al., 2011), and in Mandarin Chinese (hereafter, simply Chinese) it appears to be the syllable (Chen, Chen, \& Dell, 2002; Chen, Lin, \& Ferrand, 2003; O'Seaghdha, Chen, \& Chen, 2010). Using the implicit-priming task, J.-Y. Chen and colleagues have consistently observed syllable, but not segment, preparation effects. Kureta et al., on the other hand, found mora 
preparation effects in Japanese. To accommodate these cross-linguistic results while retaining the generality of the Levelt-type word production model, O'Seaghdha et al. recently proposed the idea of the proximate unit, which the word production system must select at the beginning of word-form encoding and which varies in grain size across languages. The syllable as the proximate unit in Chinese is consistent with a number of linguistic characteristics of this language. For examples, the structure of a Chinese syllable is simple, the number of Chinese syllables is much lower than in the IndoEuropean languages, the syllable boundary is unambiguous, resyllabification is prohibited, the syllable is the phonological domain of the tone, and the syllable corresponds to the character (a prominent unit of written Chinese).

In spite of the language-specific motivations for the syllable as the proximate unit in Chinese, in the present study we consider an alternative, task-dependent interpretation of the persistent syllable preparation effects and the lack of segment preparation effects found in the previous work. According to this interpretation, the previous results are attributed to the orthographic bias induced by the written prompt in an implicit-priming task: When the prompt is presented visually as a written word, the nature of the characters in the word may motivate the production system to put more emphasis on the syllable than on the segment. In other words, the absence of segment preparation effects in Chinese may not be intrinsic to the Chinese production system, but an artifact introduced by the syllable-biased prompt employed in the task.

The idea that orthography might have something to do with the kind of production effect observed in a language was tested recently by Verdonschot et al. (2011) in Japanese using the masked-priming paradigm. The authors observed priming effects for the mora but not for the segment, no matter whether kana (a mora-based script) or romaji (Romanized Japanese, a segment-based script) were used, which indicates that the language-specific production effect is not motivated by language-specific orthography. In the present study, we tested the same idea in Chinese, but with the implicit-priming paradigm. We did not use Romanized Chinese (pinyin in China or zhuyin in Taiwan), as this is never the normal and usual way of reading Chinese. Response times thus might be especially long if words were presented in zhuyin, and it is likely that very slow responses would discourage a head start in the homogeneous context and eliminate any preparation effect. Instead, we tested the idea with spoken prompts and with no prompts.

Experiment 1 was designed to examine whether spoken prompts might encourage segment processing (or discourage syllable processing), as compared with written prompts, such that a segment preparation effect might be observed. Spoken prompts do not involve a visual form, and hence should be less likely to bias toward syllables than written prompts could be. If the absence of a segment preparation effect in our previous work was a consequence of adopting syllablebiasing written prompts, the segment preparation effect would be expected to show up when the prompts were in spoken form, but not when they were in written form. In addition, the syllable preparation effect should be a joint function of the segment preparation effect and the syllable length (number of segments) when prompts are presented in spoken form.

The replacement of written prompts with spoken ones in Experiment 1 might not eliminate the orthographically induced syllable bias completely. This is because ample evidence has shown that orthography influences the perception and recognition of spoken words (e.g., Seidenberg \& Tanenhaus, 1979; Taft \& Hambly, 1985; Ziegler \& Ferrand, 1998; Zou, Desroches, Liu, Xia, \& Shu, 2012). Although, in an implicitpriming task, the spoken word prompt is not the word to be spoken by the participants, the recognition process of the spoken prompt might still activate the orthographic system automatically, and thus exert an influence on the production process. To eliminate any orthographically induced syllable bias more thoroughly, in Experiment 2 we adopted the picture version of the implicit-priming task, in which no prompts were used. If the absence of a segment preparation effect in our previous studies had to do with the presence of a prompt in any form, a segment preparation effect would be expected to occur once the prompt was removed from the task.

\section{Experiment 1: Associated word naming with written and spoken prompts}

\section{Method}

Participants A group of 36 students from the National Cheng Kung University were paid to take part in the experiment. They were all native speakers of Mandarin Chinese and had normal hearing and normal or corrected-to-normal vision.

Apparatus The experiment was run on an ASUS Desk PC with a 15-in. LCD screen, using DMDX Version 4.0.4.8 (Forster \& Forster, 2003). The DigitalVOX input device built into DMDX monitored the vocal input from the headset for energy above a threshold, and the response latency was measured and calculated with millisecond precision. The RecordVocal input device built into DMDX wrote the vocal input to a file, and CheckVocal Version 1.8.1 (Protopapas, 2007) was used to check the accuracy and adjust the response times (RTs) of the recorded responses.

Materials In total, 27 Chinese disyllabic word pairs were adopted from O'Seaghdha et al. (2010), each comprising a prompt and an associated target. In the syllable condition, these word pairs were divided into three groups of three homogeneous sets, each set containing three word pairs, 
such that the three targets in the same set shared an initial atonal syllable (i.e., the same syllable, disregarding tones). Within each group, the nine word pairs that formed the three homogeneous sets were regrouped to create three heterogeneous sets, such that the three targets in the same set no longer shared their initial syllables. The materials in the segment condition were constructed in the same way, with the exception that the three targets in the same homogeneous set only shared the onset segment. Across the three groups, the syllable condition and the segment condition were matched on the types of shared syllables and the types of shared segments. Three lists were prepared from these materials, such that each list included one group of materials from the syllable condition and one from the segment condition. Each participant was randomly assigned to receive just one list, and the three lists were assigned to equal numbers of participants. See Appendix A for the list of the target words. A different set of nine word pairs was used for practice.

Design Each participant was tested in either the visual or the auditory modality. The order of the conditions was counterbalanced across participants, such that half of them received the syllable condition first, and the other half the segment condition first. The three homogeneous sets and the three heterogeneous sets (i.e., all six sets) in a condition were administered in a random order, and they made up one block. This block was repeated three times. During the experiment proper, the three prompts in a set were presented six times in a random order. Altogether, each participant received 648 trials: 2 conditions (syllable, segment) $\times 2$ contexts (homogeneous, heterogeneous) $\times 3$ sets $\times 3$ blocks $\times 3$ items $\times 6$ repetitions. Modality, List, and Order were betweenparticipants factors, and the remaining factors were analyzed within participants. All participants received three practice sets before the experimental proper began.

Procedure The participants read and signed a consent form before being tested individually in a quiet room, in which they sat $60 \mathrm{~cm}$ away from the LCD screen and wore a headset. The experiment comprised a learning phase and a testing phase for each set of materials being tested. In the learning phase, the participants learned the three associated word pairs in a set until they had committed the associations to memory. In the testing phase, a trial began with a 1000 $\mathrm{Hz}$ warning tone along with two short dashed lines flanking a blank space (-- --) at the center of the screen for $200 \mathrm{~ms}$. After a blank interval of $600 \mathrm{~ms}$, a word prompt appeared for $500 \mathrm{~ms}$, and another $1,500 \mathrm{~ms}$ elapsed before the trial ended. The prompt word was presented visually in 36-point XingXiMing font (visual modality), or a prerecorded sound file (edited to $500 \mathrm{~ms}$ in duration) was played via the headset (auditory modality). The participants were told to say out loud the target word upon seeing or hearing the associated prompt word, as quickly and accurately as possible. If no response was initiated within $2,000 \mathrm{~ms}$ of the presentation of the prompt, a feedback tone of $500 \mathrm{~Hz}$ was sounded for 200 ms. The next trial began after another $200 \mathrm{~ms}$ had elapsed. The participants were allowed to take breaks during the learning phase. The entire experimental session took about $1.5 \mathrm{~h}$ to complete.

\section{Results}

Errors (incorrect responses, no responses, stuttering, responses beginning with a filled pause, and corrected responses) and extreme values (RTs less than $200 \mathrm{~ms}$ or longer than 2,000 ms) accounted for $1.47 \%$ of the trials, which were excluded from further RT analysis. Figure 1 plots the means of the RTs for correct items by context and condition for the visual and auditory modalities. As the figure shows, the mean RTs were longer in the auditory than in the visual modality. For both modalities, an effect of context appeared in the syllable condition (18 and $12 \mathrm{~ms}$ in the visual and auditory modalities, respectively) but not in the segment condition ( 3 and $2 \mathrm{~ms}$ in the visual and auditory modalities, respectively). These patterns are supported by the following analysis.

The RTs were first log-transformed before being submitted to linear mixed-effect modeling (LMM), with Participants and Items as random-effect factors (Baayen, 2008; Bates, 2005). The LMM analysis was conducted using the lme4 package in R (Version 2.13.2). The initial modeling treated three main effects (modality, context, and condition) and their interactions as fixed effects. Table 1 shows the results of the analysis. We found a main effect of modality and an interaction of context and condition. The latter represents a difference between the segment preparation effect and the syllable preparation effect. Importantly, the threeway interaction of context, condition, and modality did not reach significance, indicating a similar difference between the segment preparation effect and the syllable preparation effect for spoken and written prompts.

To ensure that the Context $\times$ Condition interaction was consistent across modalities, the analyses were conducted again, separately for the visual and auditory modalities. Both analyses showed a significant interaction of context and condition (Markov-chain Monte Carlo $p$ values [pMCMCs] = .0001 and .0113 for visual and auditory, respectively). The simple-effect analyses showed that a context effect appeared in the syllable condition (pMCMC $=.0001$ and .0001 for visual and auditory, respectively), but not in the segment condition $(\mathrm{pMCMC}=.1485$ and .5792 for visual and auditory, respectively).

The influences of three secondary variables (block, order, and list) on the results were evaluated by additionally including them as fixed-effect factors and redoing the above analyses. This time we found an effect of block, but no 
Fig. 1 Means and standard errors of correct-trial RTs in Experiment 1 (associated word naming), plotted as a function of context and condition for spoken and written prompts
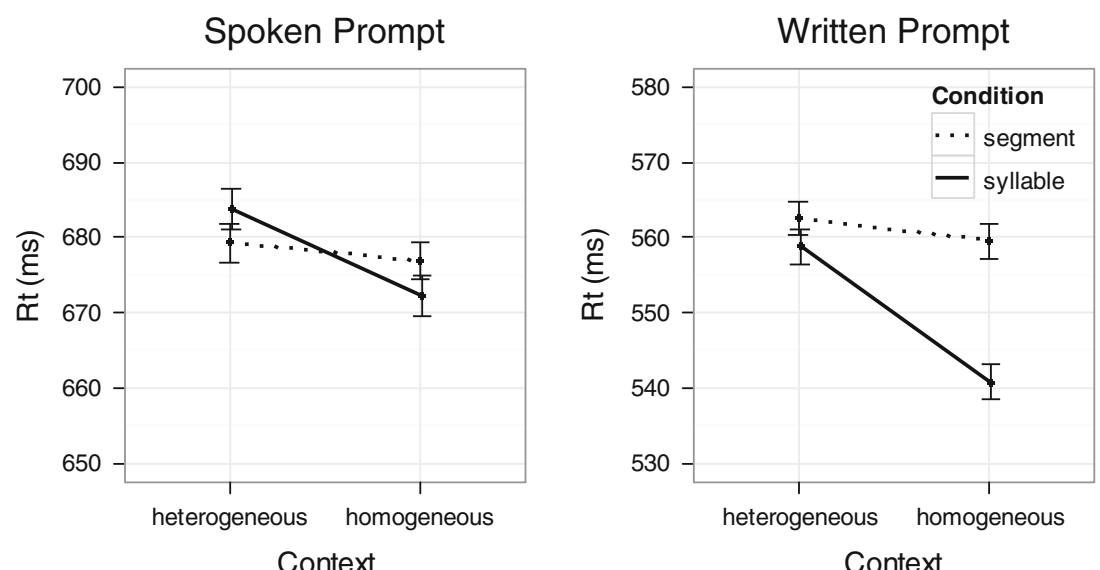

effects of order and list. The critical results remained unchanged in these analyses.

\section{Discussion}

Replacing written prompts with spoken prompts in an implicit-priming task should reduce the hypothesized orthographically induced syllable bias, but the results showed that the spoken prompts did not make the segment preparation effect more observable. Regardless of modality, little evidence emerged of a segment preparation effect. In addition, although the syllable preparation effect was reduced when the written prompt was replaced with a spoken prompt (from 18 to $12 \mathrm{~ms}$ ), the effect was clearly not segmental. The nominal value of the segment preparation effect in the spoken-prompt condition was $2 \mathrm{~ms}$, and the average syllable length of the shared syllables was 2.3 segments. Thus, if the syllable preparation effect were segmental in nature, the effect should have been around $5 \mathrm{~ms}$, but it was actually $12 \mathrm{~ms}$. The reduction of the syllable preparation effect may have been due to the fact that speaking early in the homogeneous condition might have interfered with hearing and comprehending the spoken prompt. Taken together, the absence of a segment preparation effect and the persistence of a syllable preparation effect when written were replaced with spoken prompts in an implicit-priming task indicate that the orthographic characteristics of the written prompt were not the biasing factor that favored the syllable but disfavored the segment in Chinese word-form encoding. For Experiment 2, we went on to examine whether a segment preparation effect might appear when associated word naming was replaced with picture naming, in which no prompts were used.

\section{Experiment 2: Picture naming with no prompts}

Method

Participants A group of 18 students from the National Cheng Kung University were paid to take part in the experiment. None had participated in the first experiment. All were native speakers of Mandarin Chinese and had normal hearing and normal or corrected-to-normal vision.

Table 1 Results of the linear mixed-effect model analysis in Experiment 1, showing effects for the fixed-effect factors (Context [homogeneous vs. heterogeneous], Condition [segment vs. syllable], and Modality [written vs. spoken prompt])

\begin{tabular}{lllll}
\hline & Estimate & HPD95lower & HPD95upper & pMCMC \\
\hline Intercept & 6.5030 & 6.4567 & 6.5492 & 0.0064 \\
Context & -0.0025 & -0.0114 & 0.0134 & .5770 \\
Condition & 0.0044 & -0.0044 & -0.1333 & .3371 \\
Modality & -0.1947 & -0.2550 & -0.0027 & $.0000^{*}$ \\
Context $\times$ Condition & -0.0154 & -0.0281 & 0.0079 & $.0160^{*}$ \\
Context $\times$ Modality & -0.0044 & -0.0171 & 0.0002 & .4966 \\
Condition $\times$ Modality & -0.0121 & -0.0249 & 0.0076 & .0593 \\
Context $\times$ Condition $\times$ Modality & -0.0100 & -0.0281 & .2701 \\
\hline
\end{tabular}

HPD95lower and HPD95upper are the lower and upper cutoffs, respectively, of the $95 \%$ confidence interval for the highest posterior density, based on 10,000 samples from the posterior distribution of the parameters. pMCMC stands for Markov-chain Monte Carlo $p$ value 
Design, materials, procedure, and apparatus The design and materials for this experiment were much simplified. The materials for the experimental trials were 18 line drawings of common objects, with 13 of these taken from the IPNP database (Szekely et al., 2004) and five drawn by a research assistant. These pictures assumed a common format: white on a black background, with a resolution of $300 \times 300$ pixels. Their names in Chinese were disyllabic. Half of the pictures were used for the syllable condition, and the other half for the segment condition. For each condition, the nine pictures formed three sets of three pictures each. In the homogeneous context, the names of the three pictures shared either a first syllable (the syllable condition) or a first segment (the segment condition). In the heterogeneous context, the same pictures were rearranged, such that the names of the pictures no longer shared a first syllable or first segment (see Table 2 for examples of the pictures used). The names of the pictures are listed in Appendix B. An additional nine pictures, also taken from the IPNP database and formed into three heterogeneous sets, were used for the practice trials. As in Experiment 1, each participant received a total of 648 trials: 2 conditions (syllable, segment) $\times 2$ contexts (homogeneous, heterogeneous) $\times 3$ sets $\times 3$ blocks $\times 3$ items $\times 6$ repetitions.

\section{Results}

The data were analyzed in the same way as in Experiment 1. Errors and extreme values (based on the same standards as in Experiment 1) accounted for $1.69 \%$ of the trials, which were excluded from further RT analysis. Figure 2 plots the means and standard errors of the correct-trial RTs as a function of context and condition. As the figure shows, we found a preparation effect in the syllable condition $(18 \mathrm{~ms})$ but not in the segment condition. In fact, there was actually a cost of trying to prepare for the segment $(-5 \mathrm{~ms})$.

Table 3 summarizes the results of an LMM analysis that included Participants and Items as random-effect factors, along with Context, Condition, and their interaction as fixed-effect factors. A main effect of context emerged. Importantly, the Context $\times$ Condition interaction was significant. The simple-effect analysis showed that the positive context effect in the syllable condition $(\mathrm{pMCMC}=.0001)$ and the negative context effect in the segment condition (pMCMC $=.0428)$ were both significant. The second analysis, including block and order in the model, showed results similar to those of the first analysis, with an effect of block but no effect of order. The critical results observed in the first analsis remained unchanged.

\section{Discussion}

Employing the picture-naming version of the implicitpriming task, in Experiment 2 we observed a pattern of results similar to what we found in the associate-naming versions with written and spoken prompts - that is, a significant syllable preparation effect and the absence of a segment preparation effect. Since the picture-naming version of the task included no prompts, the absence of a segment preparation effect has nothing to do with prompts. Rather, it reflects an intrinsic property of the Chinese output phonology, which is organized around syllables. When the phonological contents of a word are initially retrieved for word-form encoding, the syllables are selected first, followed by a segmental spell-out. An attempt to prepare for the segment before the syllable is selected can lead to a cost in processing.

It is worth noting that the negative segment effect serves to dismiss the argument that the absence of a segment preparation effect in Chinese is simply the result of a lesser amount of phonological overlap. Furthermore, the fact that a negative segment effect was observed in the picture-naming version of the implicit-priming task, with the help of the LMM analysis, confirms that the picture-naming version is more sensitive than the traditional associate-naming version for examining word-form encoding (Santiago, 2000), and that the LMM analysis is a more powerful technique for analyzing psycholinguistic data than is conventional analysis of variance (Baayen, 2008).

\section{General discussion}

The word production model proposed by Levelt et al. (1999) assumes that the phonological contents selected at the beginning of word-form encoding are segments rather than syllables. The same paradigms that provide evidence for

Table 2 Examples of the pictures used in Experiment 2 (from the homogeneous set /t/)

\begin{tabular}{|c|c|c|c|}
\hline Picture & & & \\
\hline Response & tuolba3 & tie 3 chui 2 & tai4yang2 \\
\hline
\end{tabular}




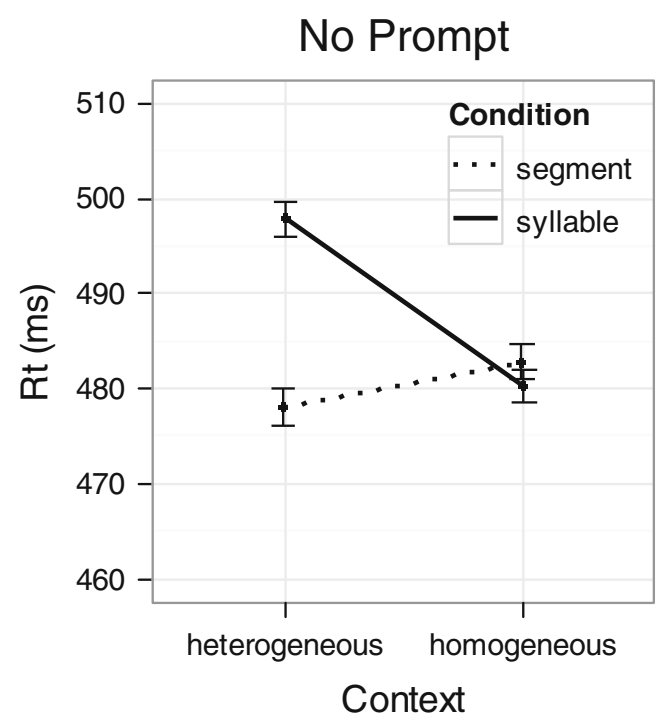

Fig. 2 Means and standard errors of correct-trial RTs in Experiment 2 (picture naming), plotted as a function of context and condition

this view in Dutch and English do not support it in Chinese and Japanese (for results from implicit priming, see Chen et al., 2002; Kureta et al., 2006; for results from masked priming, see Chen et al., 2003; Verdonschot et al., 2011). To retain the generality of the model while accommodating the cross-linguistic variations, O'Seaghdha et al. (2010) proposed the language-general proximate units principle, according to which word-form encoding starts with the first selectable phonological unit below the word level. The unit, called the proximate unit, varies in type across languages but serves the same roles. For example, it is the first unit selected for phonological encoding, and therefore is subject to slips of the tongue. At the same time, it serves to guide and constrain phonological encoding of the units below it. In addition, the proximate unit is what channels the partial phonological activation experienced in the tip-of-the-tongue state. It is also the unit that speakers are consciously aware

Table 3 Results of the linear mixed-effect model analysis in Experiment 2 , showing effects for the fixed-effect factors (Context [homogeneous vs. heterogeneous] and Condition [segment vs. syllable])

\begin{tabular}{lllll}
\hline & Estimate & HPD95lower & HPD95upper & pMCMC \\
\hline Intercept & 6.1503 & 6.0952 & 6.2088 & $.0001^{*}$ \\
Context & 0.0087 & 0.0087 & 0.0174 & $.0406^{*}$ \\
Condition & 0.0407 & 0.0403 & 0.0887 & .0972 \\
Context $\times$ & -0.0425 & -0.0424 & -0.0308 & $.0001^{*}$ \\
Condition & & & & \\
\hline
\end{tabular}

HPD95lower and HPD95upper are the lower and upper cutoffs, respectively, of the $95 \%$ confidence interval for the highest posterior density, based on 10,000 samples from the posterior distribution of the parameters. pMCMC stands for Markov-chain Monte Carlo $p$ value of while reporting the beginning of a word (O'Seaghdha \& Chen, 2009; O'Seaghdha et al., 2010).

Figure 3 illustrates a Levelt-type model modified to include proximate units. Note that nonproximate units are also included in the modified model. The nonproximate units are also selectable phonological units, but they are simply not the ones selected first. In languages in which the proximate units are segments, nonproximate units do not apply, and the word-form encoding process runs once only. In languages in which the proximate units are larger than segments, the nonproximate units also apply, and the word-form encoding process thus iterates for the nonproximate units. In Chinese, the nonproximate units might be segments. Note that any attempt to prepare for the segment in advance would violate the standard operating procedure of phonological encoding in Chinese and would result in aborting the procedure and a restart, a processing cost evidenced by the negative segment effect that we found in Experiment 2.

Why do different languages develop and employ proximate units of different grain sizes? We think the phonological characteristics of a language determine how the phonological contents of a word are organized and stored in the word-form lexicon. This, in turn, determines what unit gets selected first during word-form encoding once the contents have been retrieved. Language-specific phonological characteristics have been emphasized in our previous work and were explained again here, at the beginning of the introduction. We might add, further, that they are probably rooted in the rhythmic structure of the language. English and Dutch speech are said to be stress-timed (Abercrombie, 1967; Cutler, Mehler, Norris, \& Segui, 1986), whereas

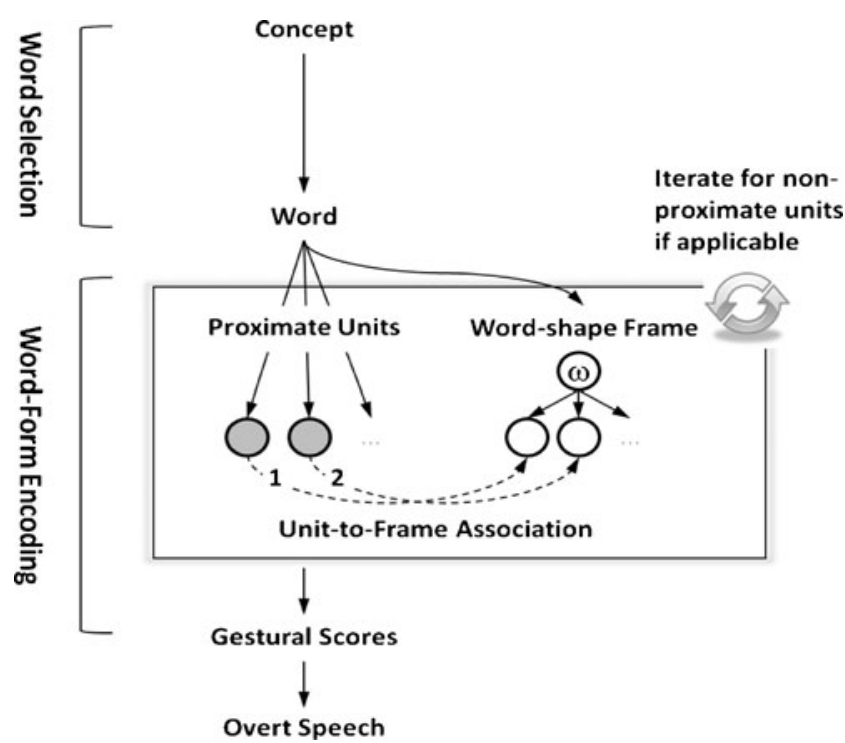

Fig. 3 Modified Levelt-type model for word-form encoding that includes the language-general proximate unit principle. Nonproximate units are also included if they apply in a language. See the text for a detailed description 
Chinese speech is syllable-timed (Mok, 2008; Tseng, Huang, \& Jeng, 1996) and Japanese speech is mora-timed (Otake, Hatano, Cutler, \& Mehler, 1993). The stress-timed rhythm entails ambisyllabicity and the need for resyllabification over a phonological word (not a lexical word). Not only are lexically stored syllables useless, but the onset segment of the phonological word also becomes particularly salient with this rhythm. In contrast, the syllable-timed rhythm entails strong and transparent syllable structures with no need for resyllabification. Storing the syllables as part of a lexical word's phonological information and retrieving them for word-form encoding seem to be the natural way for preparing to speak the word. Thus, word production systems seem to vary in whether they rely on the storage/ retrieval mechanism or the computational mechanism.

In addition to language-specific phonological characteristics, the kind of output targeted by the production system may also constrain the word-form encoding process. Chen and $\mathrm{Li}$ (2011) recently observed a segment-priming effect in a word-typing task, but not in a word-naming task. Similarly, Chen and Chen (2012) observed a segment preparation effect in an implicit-priming task when the responses were typed, but no such effect has ever been reported when the responses were spoken. The authors attributed the segment effects to the demand for segment-sized output in typing (called the output constraint hypothesis). It may be worthwhile for future work to employ the implicit-priming task and to require participants to spell out their responses in pinyin or zhuyin as another way of testing this hypothesis.

One caveat before concluding is that the hypothesized orthographically induced syllable bias may be the result of literacy. Since the participants in all of our studies have been literate speakers, this possibility could only be ruled out by future research with illiterate or congenitally blind speakers who have not been exposed to written Chinese. With this caveat in mind, we conclude that the syllable as the proximate unit in Mandarin Chinese word production is an intrinsic, and not an accidental or task-dependent, property of the production system.

Author Note This research was supported by the National Science Council (ROC), through Grant No. NSC100-2410-H-006-023-MY3 awarded to J.-Y.C. We thank Pei-Ling Lin and Chun-Qi Li for their help with the data coding and checking.

\section{Appendix A}

Table 4 Target words used in Experiment 1

\begin{tabular}{|c|c|c|c|c|c|c|c|}
\hline \multirow[b]{3}{*}{ List 1} & \multirow[b]{3}{*}{ Set } & \multicolumn{6}{|l|}{ Homogeneous } \\
\hline & & \multicolumn{3}{|l|}{ Syllable } & \multicolumn{3}{|l|}{ Segment } \\
\hline & & fei & ke & pi & $\mathrm{fl}$ & $\mathrm{k} 1$ & $\mathrm{p} 1$ \\
\hline \multirow[t]{6}{*}{ Heterogeneous } & 1 & 飛機 & 可樂 & 譬喻 & 飛機 & 可樂 & 譬喻 \\
\hline & & $\begin{array}{l}\text { fei1ji1 } \\
\text { "airplane" }\end{array}$ & ke3le4 "coke" & pi4yu4 "metaphor" & $\begin{array}{l}\text { fei1ji1 } \\
\text { "airplane" }\end{array}$ & ke3le4 "coke" & pi4yu4 "metaphor" \\
\hline & 2 & 翡翠 & 客廳 & 批評 & 憤怒 & 刊物 & 跑步 \\
\hline & & fei3cui4 "jade" & $\begin{array}{l}\text { ke4ting1 } \\
\text { "living room" }\end{array}$ & $\begin{array}{l}\text { pi1ping2 } \\
\text { "criticism" }\end{array}$ & fen4nu4 "rage" & $\begin{array}{l}\text { kan1wu4 } \\
\text { "publication" }\end{array}$ & pao3bu4 "jogging" \\
\hline & 3 & 肺癌 & 科學 & 㾒子 & 反對 & 褲子 & 撲滅 \\
\hline & & $\begin{array}{l}\text { fei4yan2 "lung } \\
\text { cancer" }\end{array}$ & $\begin{array}{l}\text { ke1xue2 } \\
\text { "science" }\end{array}$ & pi3zi5 "ruffian" & $\begin{array}{l}\text { fan3dui4 } \\
\text { "disagree" }\end{array}$ & ku4zi5 "pants" & $\begin{array}{l}\text { pulmie4 } \\
\text { "exterminate" }\end{array}$ \\
\hline List 2 & Set & fen & kan & pao & $\mathrm{f} 2$ & $\mathrm{k} 2$ & $\mathrm{p} 2$ \\
\hline \multirow[t]{6}{*}{ Heterogeneous } & 1 & 憤怒 & 刊物 & 跑步 & 翡翠 & 客廳 & 批評 \\
\hline & & fen4nu4 "rage" & $\begin{array}{l}\text { kan1wu4 } \\
\text { "publication" }\end{array}$ & pao3bu4 "jogging" & fei3cui4 "jade" & $\begin{array}{l}\text { ke4ting1 } \\
\text { "living room" }\end{array}$ & $\begin{array}{l}\text { pilping2 } \\
\text { "criticism" }\end{array}$ \\
\hline & 2 & 芬芳 ～～～～～ & 砍柴 & 泡麵 & 芬芳 & 砍柴 & 泡麵 \\
\hline & & $\begin{array}{l}\text { fen1 fang1 } \\
\text { "fragrance" }\end{array}$ & $\begin{array}{l}\text { kan3chai2 } \\
\text { "chop" }\end{array}$ & $\begin{array}{l}\text { pao4mian4 "instant } \\
\text { noodles" }\end{array}$ & $\begin{array}{l}\text { fen1 fang1 } \\
\text { "fragrance" }\end{array}$ & $\begin{array}{l}\text { kan3chai2 } \\
\text { "chop" }\end{array}$ & $\begin{array}{l}\text { pao4mian4 "instant } \\
\text { noodles" }\end{array}$ \\
\hline & 3 & 粉刷 & 看法 & 抛錨 & 犯罪 & 哭閙 & 普遍 ～～～～～～ \\
\hline & & $\begin{array}{l}\text { fen3shua1 } \\
\text { "decorate" }\end{array}$ & $\begin{array}{l}\text { kan4fa3 } \\
\text { "viewpoint" }\end{array}$ & $\begin{array}{l}\text { pao1mao2 } \\
\text { "breakdown" }\end{array}$ & $\begin{array}{l}\text { fan4zui4 } \\
\text { "crime" }\end{array}$ & $\begin{array}{l}\text { ku1nao4 } \\
\text { "distressed" }\end{array}$ & pu3pian4 "general" \\
\hline List 3 & Set & fan & $\mathrm{ku}$ & $\mathrm{pu}$ & $\mathrm{f} 3$ & $\mathrm{k} 3$ & p3 \\
\hline
\end{tabular}


Table 4 (continued)

\begin{tabular}{|c|c|c|c|c|c|c|c|}
\hline & & \multicolumn{6}{|c|}{ Homogeneous } \\
\hline & & Syllable & & & Segment & & \\
\hline \multirow[t]{6}{*}{ Heterogeneous } & 1 & 反對 & 褲子 & 撲滅 & 肺癌 & 科學 & 㾂子 \\
\hline & & $\begin{array}{l}\text { fan3dui4 } \\
\text { "disagree" }\end{array}$ & ku4zi5 "pants" & $\begin{array}{l}\text { pulmie4 } \\
\text { "exterminate" }\end{array}$ & $\begin{array}{l}\text { fei4yan2 "lung } \\
\text { cancer" }\end{array}$ & $\begin{array}{l}\text { ke1xue2 } \\
\text { "science" }\end{array}$ & pi3zi5 "ruffian" \\
\hline & 2 & 犯罪 & 哭銿 & 普遍 & 粉刷 & 看法 & 抛錨 \\
\hline & & $\begin{array}{l}\text { fan4zui4 } \\
\text { "crime" }\end{array}$ & $\begin{array}{l}\text { ku1nao4 } \\
\text { "distressed" }\end{array}$ & pu3pian4 "general" & $\begin{array}{l}\text { fen3shual } \\
\text { "decorate" }\end{array}$ & $\begin{array}{l}\text { kan4fa3 } \\
\text { "viewpoint" }\end{array}$ & $\begin{array}{l}\text { pao1mao2 } \\
\text { "breakdown" }\end{array}$ \\
\hline & 3 & 蕃茄 & 苦瓜 & 瀑布 & 蕃茄 & 苦瓜 & 瀑布 ～～～～～ \\
\hline & & $\begin{array}{l}\text { fan1qie2 } \\
\text { "tomato" }\end{array}$ & $\begin{array}{l}\text { ku3gual "bitter } \\
\text { melon" }\end{array}$ & pu4bu4 "waterfall" & $\begin{array}{l}\text { fan1qie2 } \\
\text { "tomato" }\end{array}$ & $\begin{array}{l}\text { ku3gual "bitter } \\
\text { melon" }\end{array}$ & pu4bu4 "waterfall" \\
\hline
\end{tabular}

\section{Appendix B}

Table 5 Names of the pictures used in Experiment 2

\begin{tabular}{|c|c|c|c|c|c|c|c|}
\hline & & \multicolumn{6}{|l|}{ Homogeneous } \\
\hline & & \multicolumn{3}{|l|}{ Syllable } & \multicolumn{3}{|l|}{ Segment } \\
\hline & Set & tu & mao & shan & $\mathrm{t}$ & $\mathrm{m}$ & $\mathrm{sh}$ \\
\hline \multirow[t]{6}{*}{ Heterogeneous } & 1 & 秃鷹 & 毛衣 & 扇子 & 拖把 & 玫瑰 & 樹葉 \\
\hline & & $\begin{array}{l}\text { tu1ying1 } \\
\text { "vulture" }\end{array}$ & $\begin{array}{l}\text { mao2yi1 } \\
\text { "sweater" }\end{array}$ & shan4zi5 "hand fan" & tuolba3 "mop" & $\begin{array}{l}\text { mei2gui1 } \\
\text { "rose" }\end{array}$ & shu4ye4 "leaf" \\
\hline & 2 & 吐司 & 帽子 & 山羊 & 鐵鎚 & 蜜蜂 & 沙發 \\
\hline & & tu3si1 "toast" & mao4zi5 "hat" & shan1yang2 "goat" & $\begin{array}{l}\text { tie3chui2 } \\
\text { "hammer" }\end{array}$ & $\begin{array}{l}\text { mi4fong1 } \\
\text { "bee" }\end{array}$ & sha1fa1 "sofa" \\
\hline & 3 & 兔子 & 貓咪 & 閃電 & 太陽 & 媽祖 & 手套 \\
\hline & & tu4zi5 "rabbit" & maolmil "cat" & $\begin{array}{l}\text { shan3dian4 } \\
\text { "lightning" }\end{array}$ & tai4yang2 "sun" & $\begin{array}{l}\text { ma1zu3 } \\
\text { "Mazu" }\end{array}$ & $\begin{array}{l}\text { shou3tao4 } \\
\text { "gloves" }\end{array}$ \\
\hline
\end{tabular}

\section{References}

Abercrombie, D. (1967). Elements of general phonetics. Edinburgh, U.K.: Edinburgh University Press.

Baayen, R. H. (2008). Analyzing linguistic data: A practical introduction to statistics using R. Cambridge, U.K.: Cambridge University Press.

Bates, D. (2005). Fitting linear mixed models in R. R News, 5, 27-30. Chen, J.-Y., \& Chen, T.-M. (2012). Word form encoding in Mandarin Chinese typewritten word production. In N. Miyake, D. Peebles, \& R. P. Cooper (Eds.), Building bridges across cognitive sciences around the world: Proceedings of the 34th Annual Meeting of the Cognitive Science Society (pp. 204-209). Austin, TX: Cognitive Science Society.

Chen, J.-Y., Chen, T.-M., \& Dell, G. S. (2002). Word-form encoding in Mandarin Chinese as assessed by the implicit priming task. Journal of Memory and Language, 46, 751-781.

Chen, J.-Y., \& Li, C.-Y. (2011). Word form encoding in Chinese word naming and word typing. Cognition, 121, 140-146.
Chen, J.-Y., Lin, W.-C., \& Ferrand, L. (2003). Masked priming of the syllable in Mandarin Chinese syllable production. Chinese Journal of Psychology, 45, 107-120.

Cutler, A., Mehler, J., Norris, D., \& Segui, J. (1986). The syllable's differing role in the segmentation of French and English. Journal of Memory and Language, 25, 385-400.

Forster, K. I., \& Forster, J. C. (2003). DMDX: A Windows display program with millisecond accuracy. Behavior Research Methods, Instruments, \& Computers, 35, 116-124. doi:10.3758/ BF03195503

Kureta, Y., Fushimi, T., \& Tatsumi, I. F. (2006). The functional unit of phonological encoding: Evidence for moraic representation in native Japanese speakers. Journal of Experimental Psychology: Learning, Memory, and Cognition, 32, 1102-1119.

Levelt, W. J. M., Roelofs, A., \& Meyer, A. S. (1999). A theory of lexical access in speech production. Behavioral and Brain Sciences, 22, 1-75.

Meyer, A. S. (1991). The time course of phonological encoding in language production: Phonological encoding inside a syllable. Journal of Memory and Language, 30, 69-89. 
Mok, P. P. K. (2008). On the syllable-timing of Cantonese and Beijing Mandarin. Retrieved August 28, 2012, from www.cuhk.edu.hk/ lin/people/peggy/MOK_PCC2008.pdf

O'Seaghdha, P., \& Chen, J.-Y. (2009). Toward a language-general account of word production: The proximate units principle. In N. Taatgen \& H. van Rijn (Eds.), Proceedings of the 31st Annual Conference of the Cognitive Science Society (pp. 68-73). Austin, TX: Cognitive Science Society.

O'Seaghdha, P. G., Chen, J.-Y., \& Chen, T.-M. (2010). Proximate units in word production: Phonological encoding begins with syllables in Mandarin Chinese but with segments in English. Cognition, $115,282-302$.

Otake, T., Hatano, G., Cutler, A., \& Mehler, J. (1993). Mora or syllable? Speech segmentation in Japanese. Journal of Memory and Language, 32, 258-278.

Protopapas, A. (2007). CheckVocal: A program to facilitate checking the accuracy and response time of vocal responses from DMDX. Behavior Research Methods, 39, 859-862. doi:10.3758/BF03192979

Santiago, J. (2000). Implicit priming of picture naming: A theoretical and methodological note on the implicit priming task. Psicológica, 21, 39-59.

Seidenberg, M. S., \& Tanenhaus, M. K. (1979). Orthographic effects on rhyme monitoring. Journal of Experimental Psychology: Human Learning and Memory, 5, 546-554. doi:10.1037/0278-7393.5.6.546
Szekely, A., Jacobsen, T., D’Amico, S., Devescovi, A., Andonova, E., Herron, D., \& Bates, E. (2004). A new on-line resource for psycholinguistic studies. Journal of Memory and Language, 51, 247-250. doi:10.1016/j.jml.2004.03.002

Taft, M., \& Hambly, G. (1985). The influence of orthography on phonological representations in the lexicon. Journal of Memory and Language, 24, 320-335.

Tseng, C.-H., Huang, K.-Y., \& Jeng, J.-Y. (1996). The role of syllable in perceiving spoken Chinese. Proceeding of National Science Council (ROC) Part C. Humanities and Social Sciences, 6, 7186.

Verdonschot, R. G., Kiyama, S., Tamaoka, K., Kinoshita, S., La Heij, W. L., \& Schiller, N. O. (2011). The functional unit of Japanese word naming: Evidence from masked priming. Journal of Experimental Psychology: Learning, Memory, and Cognition, 37, $1458-1473$.

Ziegler, J. C., \& Ferrand, L. (1998). Orthography shapes the perception of speech: The consistency effect in auditory word recognition. Psychonomic Bulletin \& Review, 5, 683-689. doi:10.3758/ BF03208845

Zou, L., Desroches, A., Liu, Y., Xia, Z., \& Shu, H. (2012). Orthographic facilitation in Chinese spoken word recognition: An ERP study. Beijing, China: Poster presented at the 18th Annual Meeting of the Organization for Human Brain Mapping. 